rather than rainbow trout. In contrast with the other three successful flies in this study, the Cinnamon Sedge is a close imitation of a particular genus (Limnephilus) rather than representing a broad impression of a range of flies. It is perhaps understandable that the brown trout, which has evolved in an environment of English chalkstreams and English anglers, should be more discriminating than the rainbow trout, which, although widely introduced in England in the past 50 years, evolved in tributaries of the Sacramento River in North America. ${ }^{7}$ As the rainbow trout rarely breeds in English waters, the opportunity for the species to develop skill in identifying flies by natural selection is limited.

It may be objected that our study is no more than a fishing expedition in that we had no agreed a priori hypothesis on the relative efficacy of the flies tested. Our results may therefore be regarded as hypothesis generating rather than hypothesis testing. Clearly, however, the possible prolongation of doctors' leisure time consequent on the use of unproductive trout flies has resource implications that the NHS may not readily bear. Our findings call for the urgent funding of a definitive, large multiriver trial.

We thank Stephen Jones for advice on the design, Jacqueline Birks for help with the analysis, and an anonymous reviewer for comments on an earlier draft. None of the investigators has any intention of taking the slightest notice of the results of this study.
Key messages

- Brown trout like a Cinnamon Sedge

- Black Gnats perform poorly

- Doctors are poor predictors of the utility of a fly

Contributors: BJB thought up and organised the trial. JGE analysed the results and wrote the paper. JMP trawled the archives of the Bodleian Library and contributed to the conviviality.J G G Ledingham and M S Dunnill (the two other members of the investigating group and of Merton College and New College, Oxford, respectively) helped with researching the literature and casting the flies.

Funding: None.

Competing interests: None declared.

1 Claudius Aelian. De animalium natura. Book 15. c. 200 AD. (Reprinted in Scholfield AF. On the characteristics of animals. London: Heinemann, 1959.)

Berners J. The treatyse of fyshinge with an angle. In: Wynkyn de Worde,

ed. The Boke of St Albans. 2nd ed. London: 1496. (Reprinted in Watkins MG. The treatyse of fyshinge with an angle. London: E Stock, 1880.)

3 Walton I. The compleat angler. London: 1653. (Reprinted in 1947 by J M Dent, London.)

Buckland J. The pocket guide to trout and salmon flies. London: Mitchell Beazley, 1986.

5 Halford FM. Floating flies and how to dress them. 2nd ed. London: Sampson Low, 1886.

6 Ronalds A. The flyfisher's entomology. London: Longman, Rees, Orme, Brown, Green, and Longman, 1836.

7 Frost WE, Brown ME. The trout. London: Collins, 1967.

\title{
Influence of superstition on the date of hospital discharge and medical cost in Japan: retrospective and descriptive study
}

\author{
Kenji Hira, Tsuguya Fukui, Akira Endoh, Mahbubur Rahman, Munetaka Maekawa
}

\section{Department of General Medicine and Clinical Epidemiology, Kyoto University, Sakyo-ku, Kyoto 606-8507, Japan Kenji Hira, postgraduate studen Tsuguya Fukui, professor \\ Mahbubur Rahman, postgraduate student Munetaka Maekawa, postgraduate student \\ Graduate School of Human and Environmental Studies, Kyoto University \\ Akira Endoh, postgraduate student \\ Correspondence to: Dr Hira \\ ken@kuhp. \\ kyoto-u.ac.jp}

BMJ 1998;317:1680-3

\begin{abstract}
Objectives To determine the influence of superstition about Taian (a lucky day)-Butsumetsu (an unlucky day) on decision to leave hospital. To estimate the costs of the effect of this superstition.

Design Retrospective and descriptive study. Setting University hospital in Kyoto, Japan. Subjects Patients who were discharged alive from Kyoto University Hospital from 1 April 1992 to 31 March 1995.

Main outcome measures Mean number, age, and hospital stay of patients discharged on each day of six day cycle.

Results The mean number, age, and hospital stay of discharged patients were highest on Taian and lowest on Butsumetsu (25.8 v 19.3 patients/day, $\mathrm{P}=0.0001$; 43.9 v 41.4 years, $\mathrm{P}=0.0001$; and 43.1 v 33.3 days, $\mathrm{P}=0.0001$ respectively). The effect of this difference on the hospital's costs was estimated to be 7.4 million yen $(£ 31000)$.

Conclusion The superstition influenced the decision to leave hospital, contributing to higher medical care costs in Japan. Although hospital stays need to be kept as short as possible to minimise costs, doctors should
\end{abstract}

not ignore the possible psychological effects on patients' health caused by dismissing the superstition.

\section{Introduction}

There are many superstitions in the world based on religion, old story, legend, fortune telling, and personal experience. Such superstitions influence people's behaviour in various social situations. In medicine, studies have been reported on Friday the 13th, the eight month fetus, and others. ${ }^{1-4}$ In Japan, Kaku reported that the superstition called Hinoe-Uma caused a significant increase in the induced abortion rate and a sharp decrease in the birthrate in $1966 .^{5-9}$

Belief in Taian-Butsumetsu, a superstition relating to the six day lunar calendar, is common among Japanese people and affects various social events in everyday life. For example, people tend to have wedding ceremonies on Taian (a lucky day), avoiding Butsumetsu. The figure shows the six day cycle of the lunar calendar (Sensho, Tomobiki, Senpu, Butsumetsu, Taian, and Shakku) related to the solar (Gregorian) calendar system, which was adopted in Japan in 1873. Despite this change Taian-Butsumetsu continued to gain popularity. ${ }^{10}$ 
Patients often express the wish to leave hospital on a Taian day by extending, not shortening, their stay. However, if doctors allow patients who do not need to be in hospital to extend their stay they cause an unnecessary rise in the cost of medical care. To show the effects of this behaviour we calculated the mean number of patients discharged on each day of the six day cycle and estimated the costs of any extended hospital stays.

\section{Methods}

We obtained computerised data from the register of patients discharged from Kyoto University Hospital from 1 April 1992 to 31 March 1995. We calculated the mean number, age, and hospital stay of patients discharged on Sensho, Tomobiki, Senpu, Butsumetsu, Taian and Shakku separately, excluding the discharges due to death. Since fewer patients were known to be discharged at the weekend than during the week the numbers of patients discharged on each day of the six day cycle were adjusted for days of the week as follows. Firstly, the total numbers of days for the study period were shown in a $6 \times 7$ table- that is, the six day cycle in columns and seven day cycle in rows. Next, the proportion of each day in the seven day cycle was calculated. The numbers of patients discharged on each day of the seven day cycle in a column of the six day cycle were multiplied by the corresponding proportion of the total days of the seven day cycle. And finally, these numbers were summed for each column of the six day cycle.

We estimated the effect on costs of medical care at the hospital and nationally, based on the following assumptions. Firstly, the influence of superstition is reflected in the difference between the actual and expected numbers of patients discharged on each day of the six day cycle. Secondly, if a doctor grants a patient's wish to leave hospital on Taian, it would be on the nearest Taian day before or after the initially scheduled date of discharge. Thirdly, the mean daily hospital charge is 4200-16 800 yen (£19-£75, \$30-\$120) as reported for $1997 .{ }^{11}$ Fourthly, the effect of superstition would be the same all over Japan. And, finally, the total number of patients who leave hospital in Japan is fixed at $13000000 /$ year. $^{12}$

\section{Statistical methods}

We calculated the mean and 95\% confidence intervals of the number, age, and hospital stay of discharged patients on each day of the six day cycle. Since these data did not exhibit a normal distribution we used the Kruskal-Wallis test followed by the Mann-Whitney test. The differences between days of the six day cycle with respect to sex, age, and hospital stay were examined by the $\chi^{2}$ test. A P value less than 0.01 was considered significant. Statistical analysis was performed using the SAS software package version 6.12.

\section{Results}

Of the 23677 patients discharged from the Kyoto University Hospital during the study period, 12613 $(53.3 \%)$ were female and $11064(46.7 \%)$ were male. The mean number of discharged patients was 21.6 a day with the mean age 42.3 years and the mean hospi- tal stay 37.1 days. The mean number, age, and hospital stay of discharged patients were highest on Taian and lowest on Butsumetsu (25.8 v 19.3 patients/day, $\mathrm{P}<0.0001 ; 43.9$ v 41.4 years, $\mathrm{P}<0.0001$; and $43.1 v$ 33.3 days, $\mathrm{P}<0.0001$ respectively; table). The KruskalWallis test showed significant difference among the days of this cycle regarding the mean number $(\mathrm{P}<0.0001)$, age $(\mathrm{P}<0.0001)$, and hospital stay $(\mathrm{P}<0.0001)$ of discharged patients.

The difference between actual and expected number of discharged patients on Taian days was about 771 patients over the three years. Thus about $3.3 \%$ of discharged patients were estimated to have changed their discharge day because of their belief in Taian. The ratio of the female to male patients on Taian was higher than that on other days (1.19 v 1.13), although this was not significant. The ratio of discharged patients aged $\geqslant 50$ years to those $<50$ years on Taian was significantly higher than that on other days ( $0.92 v 0.80 ; \mathrm{P}=0.001$ by $\chi^{2}$ test). The ratio of hospital stays $\geqslant 29$ days to those $<29$ days on Taian was significantly higher than that on other days $(0.71 \mathrm{v}$ $0.53 ; \mathrm{P}=0.001)$. The number of women aged 50 or more with hospital stays of at least 29 days who were discharged on Taian was 2.15 times higher than the number discharged on Butsumetsu.

\section{Economic estimation}

Given that the mean hospital charge was 12600 yen a day and that the extra patients extended their hospital stay to the nearest Taian, we estimated that the extra cost to our hospital was 7.4 million yen (£31 000) a year. However, if all the patients shortened their hospital stay to the nearest Taian, although much less likely, the saving would be 12.1 million yen.

\section{Discussion}

We found that significantly more patients were discharged on lucky days and fewer on unlucky days. There were significantly more older patients, especially women, discharged on Taian than on Butsumetsu. Since more older people tend to believe superstitions than young people, this finding further supports the intentional shift of discharge day to Taian by

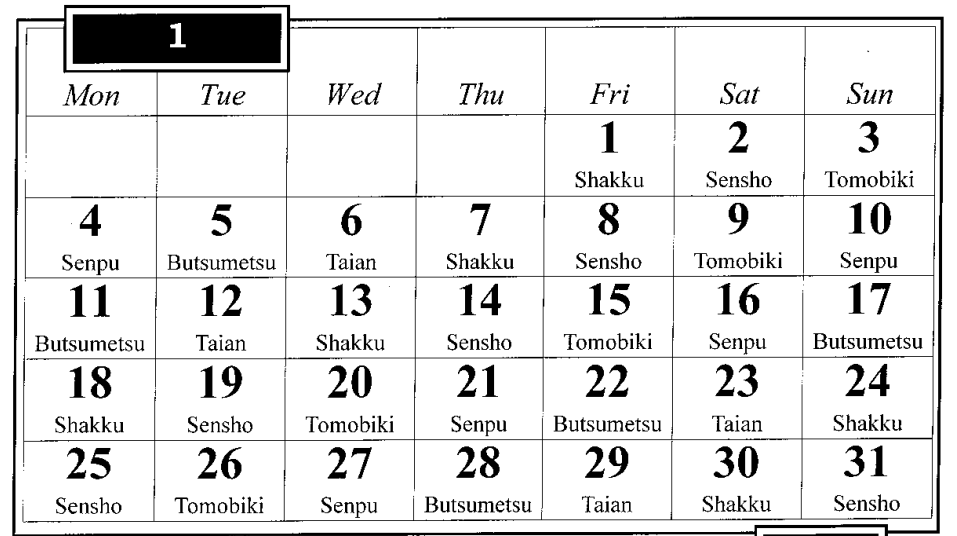

Solar and lunar calendars. Sensho is a good day for urgent business. Tomobiki is a bad omen for funerals and Buddhist services, and to hold 1999 a funeral on this day is said to be inviting another death. Senpu can be a bad day unless tasks are performed serenely. Butsumetsu means bad luck in all respects. Taian is day of good fortune in all respects, and Shakku brings bad luck in all respects except at noon. 
Data on discharged patients according to six day cycle

\begin{tabular}{|c|c|c|c|c|c|c|c|}
\hline & \multicolumn{6}{|c|}{ Six day cycle } & \multirow[b]{2}{*}{ Total } \\
\hline & Sensho & Tomobiki & Senpu & Butsumetsu & Taian & Shakku & \\
\hline No of days & 183 & 184 & 182 & 182 & 183 & 181 & 1095 \\
\hline No of patients (\%) & 3895 (16.5) & 3915 (16.5) & $3872(16.4)$ & $3504(14.8)$ & $4728(20.0)$ & $3763(15.9)$ & $23677(100)$ \\
\hline Sex ratio (female:male) & 1.11 & 1.15 & 1.13 & 1.11 & 1.19 & 1.15 & 1.14 \\
\hline \multicolumn{8}{|l|}{ No of discharged patients/day: } \\
\hline Mean $(95 \% \mathrm{Cl})^{\star}$ & $21.3(19.7$ to 22.9$)$ & 21.3 (19.7 to 22.8) & 21.3 (19.9 to 22.7) & $19.3(17.9$ to 20.6$)$ & 25.8 (24.1 to 27.6$) \dagger$ & 20.8 (19.2 to 22.3) & $21.6(21.0$ to 22.3$)$ \\
\hline Median & 23 & 24.5 & 23 & 20 & 29 & 22 & 23 \\
\hline \multicolumn{8}{|l|}{ Age: } \\
\hline Mean $(95 \% \mathrm{Cl})^{*}$ & 41.9 (41.1 to 42.6$)$ & 42.4 (41.6 to 43.1$)$ & 42.1 (41.3 to 42.8$)$ & 41.4 (40.6 to 42.2$)$ & $43.9(43.3$ to 44.6$) \dagger$ & 42.0 (41.2 to 42.7$)$ & $42.3(42.0$ to 42.6$)$ \\
\hline Median & 44 & 46 & 45 & 44 & 48 & 44 & 45 \\
\hline \multicolumn{8}{|l|}{ Distribution (patients/day): } \\
\hline$\geqslant 50$ years old ${ }^{*}$ & 9.3 & 9.6 & 9.6 & 8.5 & $12.4 \dagger$ & 9.1 & 9.7 \\
\hline$<50$ years old & 12.0 & 11.7 & 11.7 & 10.8 & 13.4 & 11.7 & 11.9 \\
\hline$\geqslant 50 /<50$ & 0.78 & 0.82 & 0.82 & 0.79 & 0.92 & 0.78 & 0.82 \\
\hline Mean $(95 \% \mathrm{Cl})^{\star}$ & 34.9 (32.4 to 37.4$)$ & 36.9 (34.1 to 39.7) & 36.1 (31.2 to 41.1) & 33.3 (30.4 to 36.2$) \dagger$ & 43.1 (39.6 to 46.7$) \dagger$ & 36.5 (32.6 to 40.4$)$ & 37.1 (35.6 to 38.5$)$ \\
\hline Median & 20 & 21 & 20 & 17 & 23 & 20 & 20 \\
\hline \multicolumn{8}{|l|}{ Distribution (patients/day): } \\
\hline$\geqslant 29$ days ${ }^{*}$ & 7.5 & 7.8 & 7.4 & $5.9 \dagger$ & $10.8 \dagger$ & 7.2 & 7.8 \\
\hline$<29$ days & 13.8 & 13.5 & 13.9 & 13.4 & 15.1 & 13.5 & 13.9 \\
\hline$\geqslant 29 /<29$ & 0.55 & 0.58 & 0.53 & 0.44 & 0.71 & 0.53 & 0.56 \\
\hline
\end{tabular}

*Significant by Kruskal-Wallis test. $†$ Significantly different from all other days by Mann-Whitney test.

superstitious patients. It would be interesting to study whether the superstition affects date of admission and operation.

Our data do not directly show that superstitious patients extended their stay. However, it is a reasonable inference that they did so because of the significantly longer hospital stay among the discharged patients on Taian as well as our clinical experiences. If the extra patients did extend their hospital stay to the nearest Taian, the cost nationally would be 1400-5320 million yen a year, accounting for $0.005-0.019 \%$ of the total national medical costs in 1997. Thus the TaianButsumetsu superstition had an important effect on the cost of medical care, although only 3.3\% of discharged patients contributed to this phenomenon.

\section{Effect of extended stay}

For patients, an extended hospital stay does not necessarily constitute financial burden because the public medical insurance system in Japan covers most of the costs. Even extremely costly care is covered by public medical insurance system once the total cost exceeds a certain level each month. This means that however much their care costs the amount paid by patients is legally fixed at a low level and they do not see the true cost of unnecessarily long hospital stays.

Doctors tend to be reluctant to refuse patients' wishes to stay longer in hospital for fear of ruining the doctor-patient relationship. Hospital management does not deter doctors from meeting these patients' wishes because of the financial incentives created by decreasing the number of vacant beds. However, longer stays do increase the risk of patients contracting nosocomial infections, which poses an ethical problem for doctors.

From the point of view of health policy unnecessary hospital stays have to be avoided to reduce the national cost of medical care. If cost keeps rising the current insurance system will have to be changed and rely more on private sector and out of pocket payments by patients. Furthermore, unnecessarily long stays prevent other patients in real need from being admitted to hospital promptly. The hospital stay in Japan is much longer than in Western countries (mean hospital stay for somatic conditions in 1989: Japan 44.9 days, Austria 5.4 days, United States 6.5 days, Canada 11.4 days $^{13}$ ). Our data show that superstitious belief is likely to be contributing, although in a minute portion, to this long hospital stay in Japan.

\section{Psychological effect of superstition}

An action against superstitious belief could have a negative effect on the health of some patients. In a study on the relation between superstition and health, Scanlon et al reported that there were more hospital admissions as a result of traffic accidents on Friday the 13th (an unlucky day in Western culture) than on other Fridays. ${ }^{2}$ Superstition may have a similar influence on health as the placebo effect, in which patients' health improves after a dummy treatment because of their expectations or belief. ${ }^{14-16}$ Furthermore, if patients have a say in when they are discharged from hospital, the "locus of control" is put in their hands to some extent, which may add to the beneficial effect. Strong action against superstition, however, may distress patients and lead to a deterioration in their health. ${ }^{17}$ In this context, doctors should pay special attention to patients with somatisation (such as those with depression or anxiety disorders). The relationship between TaianButsumetsu belief and health outcome is an intriguing question for prospective study.

\section{Conclusion}

Belief in Taian-Butsumetsu certainly influences the decision to leave hospital. The superstition related behaviours of patients cause financial and complex psychosocial problems. Although the costs of unnecessarily extended hospital stay are appreciable, no data exist on the psychological impact of the superstition. Doctors should explain drawbacks of unnecessarily 
Key messages

- Belief in Taian-Butsumetsu, a superstition relating to the six day lunar calendar, is common among Japanese people

- This study showed that the mean number of patients discharged on Taian (a lucky day) is the highest and that on Butsumetsu (an unlucky day) is the lowest

- Patients discharged on Taian were older, were more likely to be female, and had longer hospital stays than those discharged on other days

- The findings suggest that patients were extending their stay to leave hospital on Taian

- This superstitious belief increased the cost of medical care in Japan

extending hospital stay to the patients while taking into consideration the possible psychological impact of the superstition on health.

This study was presented at the 2nd Asian-Pacific congress of epidemiology, Tokyo, Japan, on 28 January 1998. We thank Mr Gert van Tonder of the Graduate School of Human and Environmental Studies at Kyoto University for his linguistic help and Mr Masahiro Natsume of Medical Informatics Department at Kyoto University (Kyoso Computer Co Ltd ES3 Implementation Department) for data collection.

Contributors: $\mathrm{KH}$ initiated the research, conducted analysis of the data and wrote the paper. TF participated in all processes and is guarantor for this paper. AE participated in data collection and discussion. MR and MM participated in the analysis of the data and discussion.

Funding: None

Competing interest: None declared.

1 Scott R, Scott H. Crocodile bites and traditional beliefs in Korogwe District, Tanzania. BMJ 1994;309:1691-2.

2 Scanlon TJ, Luben RN, Scanlon FL, Singleton N. Is Friday the 13th bad for your health? $B M J 1993 ; 307: 1584-6$.

3 Reiss RE, Ash AD. The eighth-month fetus: classical sources for a modern superstition. Obstet Gynecol 1988;71:270-3.

4 Blacher RS. Clusters of disaster: superstition and the physician. Gen Hosp Psychiatry 1983;5:279-84.

5 Kim YS. Fertility of the Korean populationin Japan influenced by a folk superstition in 1966. J Biosoc Sci 1979;11:457-64.

6 Kaku K. Were girl babies sacrificed to a folk superstition in 1966 in Japan? Ann Hum Biol 1975;2:391-3.

7 Kaku K. Increased induced abortion rate in 1966, an aspect of a Japanese folk superstition. Ann Hum Biol 1975;2:111-5.

8 Kaku K, Matsumoto YS. Influence of a folk superstition on fertility of Japanese in California and Hawaii, 1966. Am J Public Health 1975;65:170-4

9 Kaku K. Are physicians sympathetic to superstition? A study of Hinoe-Uma. Soc Biol 1972;19:60-4.

10 Uchida M. The calendar's tale for 12 months. Tokyo: Yuzankaku, 1991:10610.

11 Survey Department of Institute of Social Insurance. Drug tariff. Tokyo: Institute of Social Insurance, 1997.

12 Statistics and Information Department. Patient survey. Tokyo: Ministry of Health and Welfare, 1993:566.

13 Organisation for Economic Cooperation and Development. OECD health system facts and trends 1960-1991. Paris: OECD, 1993:215.

14 Oh VM. The placebo effect: can we use it better? BMJ 1994;309:69-70.

15 Dobrilla G, Scarpignato C. Placebo and placebo effect: their impact on the evaluation of drug response in patients. Dig Dis 1994;12:368-77.

16 Kleijnen J, de Craen AJ, van Everdingen J, Krol L. Placebo effect in double-blind clinical trials: a review of interactions with medications. Lancet 1994;344:1347-9.

17 Edward A, Walker JK, Wayne JK. Psychological factors affecting medical conditions and stress responses. In: Stoudemire A, ed. Human behavior. Philadelphia: Lippincott, 1990:64-83.

\title{
Life is sweet: candy consumption and longevity
}

\author{
I-Min Lee, Ralph S Paffenbarger Jr
}

Our attitude towards candy- -if it tastes that good, it can't be healthy"-betrays society's puritanical stance towards pleasure. Candy has been blamed for various ills, including hyperactivity in children; however, clinical trials have not supported this. ${ }^{1}$

Candy-sugar confectionery and chocolate-is not a recent invention: the ancient Arabs, Chinese, and Egyptians candied fruits and nuts in honey, and the Aztecs made a chocolate drink from the bean of the cacao tree. Today, Americans gratify themselves with, on average, $5.4 \mathrm{~kg}$ of sugar candy and $6.5 \mathrm{~kg}$ of chocolate per person annually. ${ }^{2}$

Since candy has existed for centuries, we surmised that it cannot be totally unhealthy. We decided to investigate whether candy consumption was associated with longevity.

\section{Subjects, methods, and results}

Subjects were from the Harvard alumni health study, an ongoing study of men entering Harvard University as undergraduates between 1916 and 1950. We included 7841 men, free of cardiovascular disease and cancer, who responded to a health survey in 1988 providing information on consumption of candy.
We asked about the average number of servings of candy eaten in the past year. Response options ranged from "almost never" to " $6+$ per day." In analyses, we regarded as non-consumers of candy the men who answered "almost never." The survey also asked about other health habits (see table). We obtained death

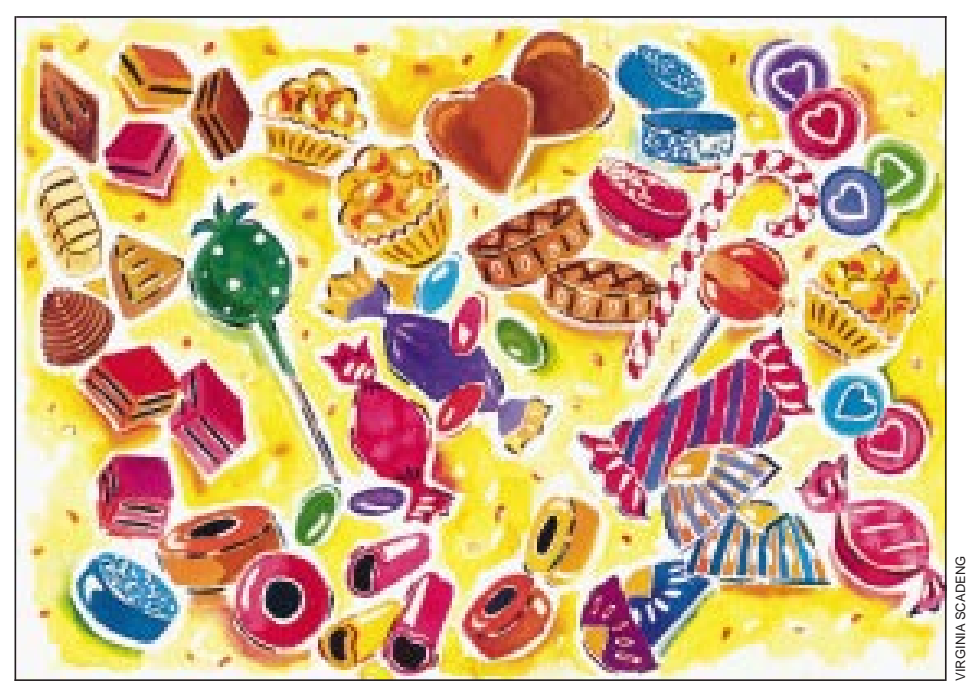

